\title{
Formulation and Evaluation of Colon Targeted Drug Delivery System of Budesonide Using Xylan as a Carrier
}

\author{
Subhendu S. Mishra*, Rajesh Ku. Nayak, S.N. Das
}

Gayatri College of Pharmacy, Gayatri Vihar, Jamadarpali, Sambalpur, Odisha.

*Corresponding Author's E mail: sekhar.subhendu@gmail.com

Received 23 July 2020; Revised 28 July 2020; Accepted 12 Aug. 2020, Available online 10 October 2020

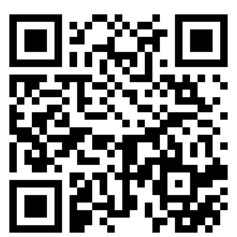

Cite this article as: Mishra SS, Nayak RK, Das SN. Formulation and Evaluation of Colon Targeted Drug Delivery System of Budesonide Using Xylan as a Carrier. 2020; 9(4): 98107.

https://dx.doi.org/10.38164/AJPER/9.3.2020.107-115.

\begin{abstract}
Budesonide has been identified as a potential candidate to treat cancer particularly colorectal cancer. High dose is required in order to make sufficient quantity available at the desired site to elicit therapeutic response. Budesonide gets absorbed in upper part of intestine making its availability in the colon extremely low. Colon targeting approach with xylan matrix tablet of Budesonide hold tremendous potential for treatment of colon cancer. In the present research work, to prepared colon targeted matrix tablet investigate the release profile of budesonide from xylan based matrix tablets and attempts were also made to explore the feasibility of xanthan gum, guar gum and pectin as colon specific carrier for budesonide. The matix tablet was prepared four different formulations with different percentage of xylan. After evaluation of physical properties of tablet, the in vitro release study was performed in $0.1 \mathrm{~N} \mathrm{HCl} \mathrm{pH} 1.2$ for $2 \mathrm{hrs}$, the dissolution medium was replaced with $\mathrm{pH} 7.4$ for $3 \mathrm{hrs}$ and then replaced with phosphate buffer $\mathrm{pH} 6.8$ next $19 \mathrm{hrs}$. the in-vitro dissolution studies it was found to be that formulation F1 with $10 \%$ Xylan, F2 with 20\% Xylan, F3 with 30\% Xylan and F4 with $40 \%$ Xylan all retard drug release in the stomach and small intestine effectively. F1 Xylan (10\%) \& F3 Xylan (30\%) emerged to be best because it exhibits the best overall general appearance, hardness of $6.2 \pm 0.498 \mathrm{Kg} / \mathrm{cm}^{2}$, friability of $0.19802 \%$, percentage drug released $53.51 \pm 0.850 \&$ hardness of $5.9 \pm 0.124 \mathrm{Kg} / \mathrm{cm}^{2}$, friability of $0.2004 \%$, percentage drug released $42.75 \pm 0.106$ without rat caecal content at the end of $24 \mathrm{~h}$ invitro dissolution studies respectively. the matrix formulation containing $\mathbf{1 0 \%}$ Xylan and $\mathbf{3 0 \%}$ xylan is most like to target budesonide to colon without being release significantly in stomach \& small intestine.
\end{abstract}

Keywords: Colon Targeted drug delivery system, Budesonide, Xylan.

\section{INTRODUCTION}

The colon is a site where both local and systemic delivery of drugs can take place. Local delivery allows topical treatment of inflammatory bowel disease ${ }^{1,2}$. Specific targeting of drugs to the colon is recognized to have several therapeutic advantages. Drugs, which are destroyed by the stomach acid and / or metabolized by pancreatic enzymes, are slightly affected in the colon, and sustained 
colonic release of drugs can be useful in the treatment of nocturnal asthma, angina pectoris and arthritis. Treatment of colonic diseases such as ulcerative colitis, colorectal cancer and Crohn's disease is more effective with direct delivery of vermicides and colonic diagnostic agents require smaller doses ${ }^{3}$. The colon is attracting interest as a site where poorly absorbed drug molecule may have an improved bioavailability ${ }^{4}$.

The bacterial enzymes of the colon degrade the carrier polymer in a well-defined way and release the content for localized colonic delivery or systemic absorption through colon. Natural polysaccharides are now extensively used for the development of solid dosage forms for delivery of drug to the colon. The rationale for the development of a polysaccharide based delivery system for colon is the presence of large amount of bacteria in the human colon as the colon is inhabited by a large number and variety of bacteria which secrete many enzymes e.g. $\beta$-D-glucosidase, $\beta$ D-galactosidase, amylase, pectinase, xylanase, $\beta$-D-xylosidase, dextranase, etc. A large number of polysaccharides have already been studied for their potential as colon-specific drug carrier systems, such as chitosan, pectin, chondroitin sulphate, cyclodextrin, dextrans, guar gum, inulin, amylase, xylan and locust bean gum. Natural polysaccharides remain undigested in the stomach and small intestine and are degraded by the enzymes released by bacteria present in the colon.

Budesonide has a high glucocorticoid effect and a weak mineralocorticoid effect. It binds to the glucocorticoid receptor with a higher binding affinity than cortisol and prednisolone. When budesonide is systemically administered, suppression of endogenous cortisol concentrations and an impairment of the hypothalamus-pituitary-adrenal (HPA) axis function has been observed. Furthermore, a decrease in airway reactivity to histamine and other entities has been observed with the inhaled formulation ${ }^{5-7}$. Colon targeting approach with xylan matrix tablet of Budesonide hold tremendous potential for treatment of colon cancer.

Keeping the above in view attempts have been made to investigate the release profile of Budesonide from xylan based matrix tablets. Attempts were also made to explore the feasibility of xanthan gum, guar gum and pectin as colon specific carrier for Budesonide.

\section{MATERIALS AND METHODS}

\section{Material}

Budesonide was a gift sample from Avik Pharma Pvt. Ltd., Vapi, Gujarat. (India). Xylen was purchased from Himedia laboratory, Mumbai, Microcrystallin cellulose (MCC), Talc and Magnessium stearate was purchased from loba chemical for this study. All reagents and solvents used were of analytical grade satisfying pharmacopoeial standards. 


\section{Method}

\section{Formulation of Colon Targeted Matrix Tablet:}

Budesonide was chosen as model drug which is poorly soluble in water. Matrix tablet of Budesonide were prepared by the direct compression technique. MCC was used as diluent and the mixture of talc \& magnesium stearate at 2:1 ratio was used as lubricant. The composition of different matrix formulation used in the study containing $75 \mathrm{mg}$ of Budesonide given in table 1.

Table 1. Composition of colon targeted matrix tablet of Budesonide

\begin{tabular}{|l|l|l|}
\hline Sr No. & Ingredients & Qty. taken \\
\hline 1 & Budesonide & $15 \%$ \\
\hline 2 & Xylan & $10-40 \%$ \\
\hline 3 & Mcc & qs $100 \%$ \\
\hline 4 & Talc & $2 \%$ \\
\hline 5 & Magnesium stearate & $1 \%$ \\
\hline
\end{tabular}

Four different formulation having different quantities of xylan (10 to $40 \%$ of total weight) were prepared by direct compression method. The tablets were prepared as described above. The composition of different formulations is shown in Table 2.

Table 2. Formulation of colon targeted matrix tablet of Budesonide

\begin{tabular}{|c|c|c|c|c|c|}
\hline \multirow[t]{3}{*}{ S. No. } & \multirow{3}{*}{$\begin{array}{l}\text { Tablet } \\
\text { Ingredients } \\
(\mathrm{mg} / \mathrm{tab})\end{array}$} & \multicolumn{4}{|c|}{ Formulation code } \\
\hline & & F1 & F2 & F3 & F4 \\
\hline & & $10 \%$ & $20 \%$ & $30 \%$ & $40 \%$ \\
\hline 1 & Budesonide & 9 & 9 & 9 & 9 \\
\hline 2 & xylan & 50 & 100 & 150 & 200 \\
\hline 3 & Mcc & 360 & 310 & 260 & 210 \\
\hline 4 & Talc & 10 & 10 & 10 & 10 \\
\hline 5 & $\begin{array}{l}\text { Magnesium } \\
\text { stearate }\end{array}$ & 5 & 5 & 5 & 5 \\
\hline
\end{tabular}




\section{Evaluation of Colon Targeted Matrix Tablet of Budesonide}

\section{General Appearance and Physical Parameters}

\section{Thickness of tablets}

Vesicle size, size distribution and zeta potential were determined by Dynamic Light Scattering system by Malvern Zetasizer.

\section{Vesicle morphology}

The diameter of vesicle in a transferosome can be determined by dynamic light scattering method. The samples are passed through $0.2 \mathrm{~mm}$ diameter of membrane filter. Before the samples are prepared by distilled water. Filtered sample is diluted with saline which is also filtered. Then size measurement is done by dynamic scattering method. Although the vesicle of transferosome can be visualized by TEM. Stability of the vesicle determined by size and structure of the vesicle. Mean size of the vesicles is performed by DLS method. System by Malvern Zetasizer.

\section{Weight variation test:}

The USP weight variation test is run by weighing 20 tablets individually, calculating the average weight and comparing the individual tablet weights to the average. The tablets meet the USP test if no more than 2 tablets are outside the percentage limit and if no tablet differs by more than 2 times the percentage limit ${ }^{7,8}$.

\section{In-vitro Drug Release study:}

Budesonide matrix tablet release from was performed by dissolution test apparatus USB type I (paddle method). The test was performed using $900 \mathrm{ml}$ of $0.1 \mathrm{~N} \mathrm{HCL}$ at $37^{0} \pm 0.5^{\circ} \mathrm{C}$ and $100 \mathrm{rpm}$ for first 2 hrs. Then replaced with $7.4 \mathrm{pH}$ phosphate buffer and continued for $24 \mathrm{hrs}$. A liquot volume of $5 \mathrm{ml}$ was withdrawn at regular intervals and replaced with fresh buffer diluted. The samples were replaced with fresh dissolution medium. The sample was analysed for the drug content by measuring absorbance by $272 \mathrm{~nm}$ in double beam spectrophotometer ${ }^{11-15}$.

\section{. RESULTS AND DISCUSSION:}

The prepared matrix tablets were subjected to post compression parameter i.e. thickness, weight variation, hardness, friability, content uniformity. All the matrix tablet formulation complies for all the physical parameter and drug content uniformity. The results are as follows. 
Table 5. Characteristics of xylan based colon targeted matrix tablet of Budesonide

\begin{tabular}{|c|c|c|c|c|c|}
\hline $\begin{array}{c}\text { Formulation } \\
\text { code }\end{array}$ & $\begin{array}{c}\text { Thickness } \\
(\mathbf{m m})\end{array}$ & Weight $(\mathbf{m g})$ & $\begin{array}{c}\text { Hardness } \\
(\mathbf{k g} / \mathbf{c m} 2)\end{array}$ & $\begin{array}{c}\text { Friability } \\
(\%)\end{array}$ & $\begin{array}{c}\text { Content } \\
\text { uniformity (\%) }\end{array}$ \\
\hline F1 & $4.1 \pm 0.0816$ & $509.05 \pm 0.639$ & $5.7 \pm 0.498$ & $0.153 \pm 0.18$ & $89.59 \pm 0.44$ \\
\hline F2 & $3.8 \pm 0.1247$ & $504.7 \pm 0.997$ & $5.8 \pm 0.286$ & $0.168 \pm 0.29$ & $89.96 \pm 1.60$ \\
\hline F3 & $4.4 \pm 0.3741$ & $507.1 \pm 0.719$ & $5.9 \pm 0.124$ & $0.208 \pm 0.27$ & $94.15 \pm 0.67$ \\
\hline F4 & $4.2 \pm 0.4784$ & $502.3 \pm 0.714$ & $5.7 \pm 0.329$ & $0.183 \pm 0.19$ & $93.99 \pm 2.09$ \\
\hline
\end{tabular}

Table 6. Result of in-vitro drug release study of colon targeted matrix tablet formulation of Budesonide

\begin{tabular}{|c|c|c|c|c|}
\hline \multirow{2}{*}{ Time(hrs) } & \multicolumn{4}{|c|}{ Cumulative \% drug release } \\
\cline { 2 - 5 } & F1 & F2 & F3 & F4 \\
\hline 2 & $2.25 \pm 0.091$ & $1.255 \pm 0.154$ & $0.790 \pm 0.004$ & $0.533 \pm 0.094$ \\
\hline 5 & $4.03 \pm 0.544$ & $3.66 \pm 0.590$ & $2.72 \pm 0.078$ & $3.47 \pm 0.340$ \\
\hline 7 & $7.53 \pm 0.624$ & $11.38 \pm 0.86$ & $6.54 \pm 0.018$ & $7.43 \pm 0.463$ \\
\hline 9 & $9.46 \pm 0.661$ & $12.87 \pm 0.50$ & $10.74 \pm 0.023$ & $11.93 \pm 0.735$ \\
\hline 12 & $13.29 \pm 0.92$ & $18.83 \pm 0.162$ & $15.33 \pm 0.056$ & $16.98 \pm 0.700$ \\
\hline 15 & $23.26 \pm 0.665$ & $25.76 \pm 0.994$ & $21.48 \pm 0.004$ & $22.38 \pm 0.912$ \\
\hline 18 & $39.49 \pm 0.654$ & $30.75 \pm 0.515$ & $27.92 \pm 0.011$ & $28.51 \pm 0.354$ \\
\hline 21 & $48.25 \pm 0.628$ & $39.20 \pm 0.932$ & $35.04 \pm 0.023$ & $35.05 \pm 0.929$ \\
\hline 24 & $53.51 \pm 0.850$ & $44.21 \pm 0.330$ & $42.75 \pm 0.106$ & $42.67 \pm 0.599$ \\
\hline
\end{tabular}




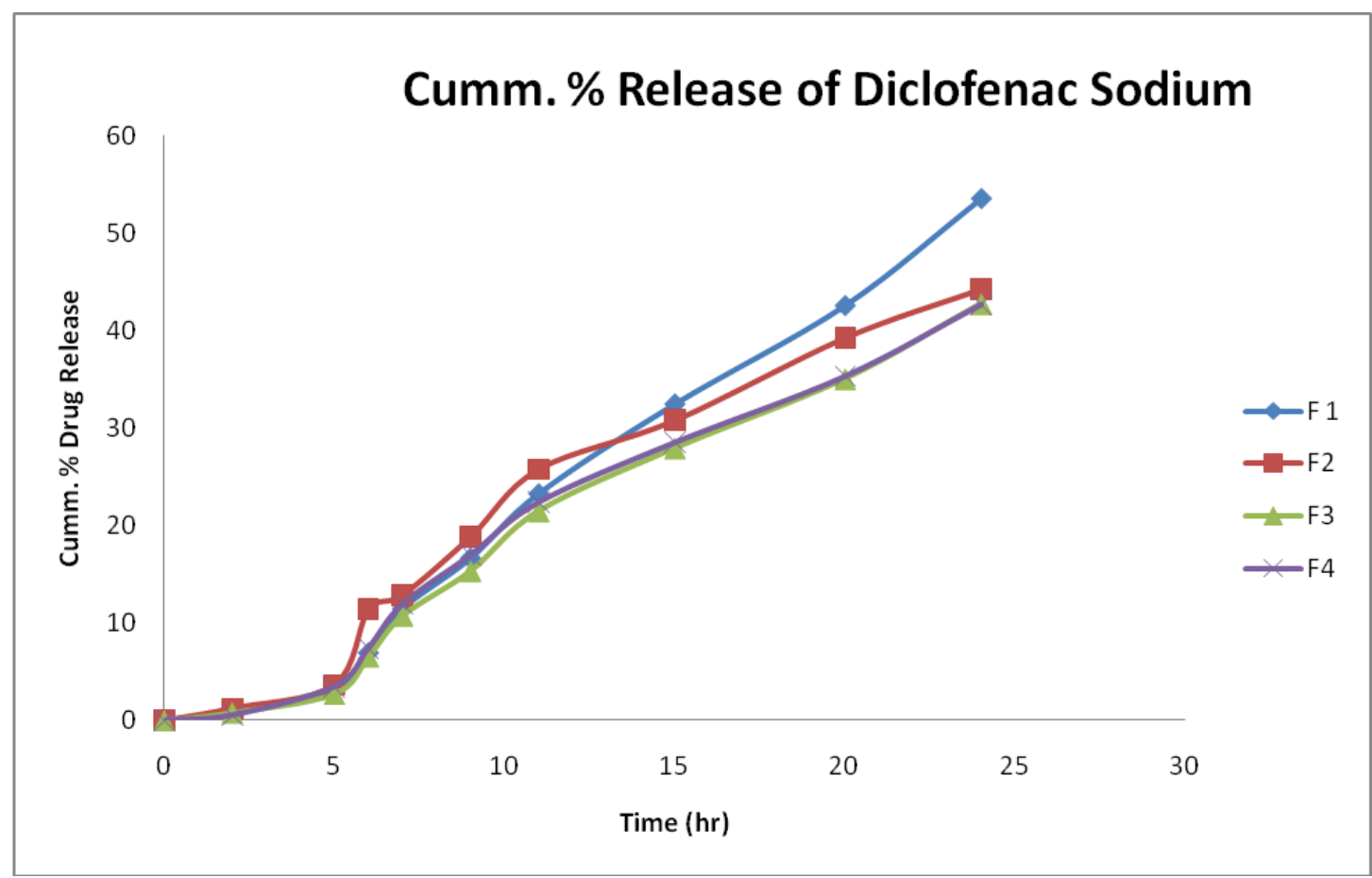

Fig. 1. Cumulative percent of Budesonide released from colon targeted matrix tablet containing varying proportion of xylan in absence of rat caecal content.

The in-vitro dissolution studies it was found to be that formulation F1 with $10 \%$ Xylan, F2 with $20 \%$ Xylan, F3 with $30 \%$ Xylan and F4 with $40 \%$ Xylan all retard drug release in the stomach and small intestine effectively. From that it can be concluded that the formulations containing $10 \%, \mathbf{2 0 \%}, \mathbf{3 0 \%}$ and $\mathbf{4 0} \%$ of Xylan all target the colon in the form of colon targeted matrix tablet.

\section{CONCLUSION}

The colon targeted matrix tablet formulations of Budesonide were prepared by direct compression technique using various proportion of xylan as polymer. Four batches were prepared with various percentage of xylan to retard the drug release in to the stomach \& small intestine.

Budesonide, a widely used non-steroidal anti-inflammatory drug has recently been found having high potential in colon cancer treatment. However, this suffers from one disadvantage i.e. on oral administration it gets absorbed in upper part of the intestine making its availability in the colon extremely low.

All the colon targeted matrix formulations prepared were evaluated for physicochemical parameters such as appearance, physical properties, drug content and in-vitro dissolution studies. All the physical characteristics of the formulations like thickness, hardness, friability, drug content, and in vitro dissolution study were found to be well within the limits and official standards. From the in-vitro dissolution studies it was found to be that formulation F1 with $10 \%$ Xylan, F2 with 
$20 \%$ Xylan, F3 with $30 \%$ Xylan and F4 with $40 \%$ Xylan all retard drug release in the stomach and small intestine effectively. From that it can be concluded that the formulations containing $10 \%, 20 \%, 30 \%$ and $40 \%$ of Xylan all target the colon in the form of colon targeted matrix tablet.

\section{REFERENCE:}

1. Philip AK, Philip B. Oman Medical Journal., 2010, 25, 70-78.

2. Akala EO, et al. Drug Dev Ind Pharm., 2003, 29, 375.

3. Vinay KV, Sivakumar T. Tamizh. Int J Pharm Biomed Sc.i., 2011, 2, 1, 11-19.

4. Shailendra W, Poonam P. International Journal of Pharmaceutical Sciences Review and Research. 2011; 6 (2): 031.

5. Lachman L, Liberman HA, Kanig JL. The theory and practice of industrial pharmacy. $3^{\text {rd }}$ edition, Varghese publishing house, Bombay, 1987, 52-71.

6. Remington. The science and practice of pharmacy. 20th edition Vol-I. Page NO. 939-940.

7. Lachman L, Lieberman HA, Kanig JL. The theory \& practice of industrial pharmacy. Mumbai: Varghese Publishing House, 1987; p. 293.

8. Pharmacopoeia of India, Controller of Publications, Delhi, 1996.

9. Krishnaiah YSR, Satyanarayana V, Dinesh Kumar B, Karthikeyan RS, Bhaskar P. In vivo pharmacokinetics in human volunteers: oral administered guar gum-based colon-targeted 5fluorouracil tablets. European Journal of Pharmaceutical Sciences. 2003; 19 : 355-362.

10. Krishnaiah YSR, Karthikeyan RS, Bhaskar P, Satyanarayana V. Bioavailability studies on guar gum-based three-layer matrix tablets of trimetazidine dihydrochloride in human volunteers Journal of Controlled Release. 2002; 83: 231-239.

11. Libo Yang, James SC, Joseph A. Fix. Colon-specific drug delivery: new approaches and in vitro/in vivo evaluation. International Journal of Pharmaceutics. 2002; 235:1-15.

12. Sinha VR, Rachna Kumaria. Coating polymer for colon specific drug delivery: a comparative in vitro evaluation. Acta Pharma. 2003; 53: 41-47.

13. Jain NK and Khar RK. Controlled and novel drug delivery, $1^{\text {st }}$ edition, Vallabh Prakashan, New Delhi, 2002; 218-256.

14. Basit AW, Lee FS, Michael N. The properties of amylose-ethyl cellulose films cast from organic-based solvents as potential coatings for colonic drug delivery. European Journal of Pharmaceutical Sciences. 2000; 11: 133-139.

15. Libo Yang, James SC, Joseph A. Fix. Colon-specific drug delivery: new approaches and in vitro/in vivo evaluation. International Journal of Pharmaceutics. 2002; 235: 1-15. 


\section{CONCLUSION:}

From this study, it was concluded that the transferosomal formulations of curcumin, with high EE $\%$ and small particle size. Also, the preparation of curcumin as transfersomal gel has the ability to overcome the barrier properties of the skin and increase the drug release.

\section{REFERENCE:}

1. Ceve G. Transferosomes, liposomes and other lipid suspensions on the skin: permeation enhancement, vesicle penetration, and transdermal drug delivery. Crit. Rev. Ther. Drug Carrier Sysm. 1996; 257-388.

2. Ogihara U, Sasaki T, Toyama H, Sneha OM, Nishigori H. Rapid diagnostic imaging of cancer using radiolabeled liposomes. Cancer. Detect. Prev. 1997; 490-496.

3. Prajapati S. T, Patel C.G and Patel C.N, “ Transferosome: A vesicular carrier system for Transdermal drug delivery.” Asian journal of Biochemical and Pharmaceutical Research, $2011 ; 1: 507-524$.

4. Brondsted H, Kopecek J, Harland RS, Prud'homme RK Eds. In Polyelectrolyte Gels. ACS Symposium Series 480. American Chemical Society. Washington, DC, 1992; Chapter 17.

5. Kunal Pal, Banthia AK and Majumdar DK. Starch based hydrogel with potential biomedical application as artificial skin. African Journal of Biomedical Research 2006; 9: 23-29.

6. Yasuda $\mathrm{K}$ et al., Biomechanical properties of high -toughness double network hydrogels. Biomaterials 2005; 26: 4468-4475. 
7. Patel R, Singh SK, Singh S, Sheth NR, Gendle R. Development and Characterization of Curcumin Loaded Transfersome for Transdermal Delivery. J. Pharm. Sci. \& Res. 2009; 1(4): 71-80.

8. Jain CP, Vyas SP and Dixit VK. International Journal of Pharmaceutics, 2006; 68: 575-578.

9. Elsayed MMS, Abdallah OY and Nagar VF. International Journal of Pharmaceutics. 2006; 322: 60-66.

10. Duangjit S, Opanasopit P, Rojanarata T, Ngawhirunpat T. Evaluation of meloxicam-loaded cationic transfersomes as transdermal drug delivery carriers. AAPS PharmSciTech. 2013; 14:133-40.

11. Jaiswal P, Kesharwani S, Kesharwani R, Patel D, Ethosome: A new technology used as topical $\&$ transdermal delivery system. Journal of Drug Delivery and Therapeutics. 2016; 6(3):7-17.

12. Modi CD and Bharadia PD, "Transfersomes: New Dominants for Transdermal Drug Delivery", American Journal of Pharmtech Research. 2012; 2(3):71-91.

13. Cevc G, Blume G, Scha“tzlein A. Transferosomes-mediated transepidermal delivery improves the regiospecificity and biological activity of corticosteroids in vivo. J Control Rel. 1997; 45: $211-26$.

14. Jivrani Shilpa D and Patel Vijay K. Formulation, Development and Evaluation of Niosomal Drug Delivery System for Clindamycin Phosphate, Pharma Science Monitor. 2014; 5(2): 256274.

15. Mishra $M$ and Biswal P. Complexation, Optimization, Formulation development and characterization of clindamycin phosphate gel using zinc acetate dehydrate, international jouranal of pharmacy, 2012; 2(3):472-486. 